\title{
O agente econômico e suas relações \\ Identificando concorrentes na política antitruste
}

Gustavo Gomes Onto

Introdução

O Conselho Administrativo de Defesa Econômica (Cade), órgão administrativo e judicante vinculado ao Ministério da Justiça, é responsável pela chamada política de defesa da concorrência ou política antitruste. Essa política pública baseia-se em uma premissa central do liberalismo econômico que afirma que situações de maior concorrência nos mercados trazem maiores benefícios econômicos para consumidores e para as economias nacionais. A concorrência entre as empresas pela venda de produtos e serviços permitiria aos consumidores comprar produtos a preços menores e tornaria as empresas mais inovadoras e produtivas (Hovenkamp, 2005). $\mathrm{Na}$ prática, o órgão brasileiro que implementa essa política tem a tarefa de investigar concentrações e práticas empresariais, buscando verificar se essas infringem a chamada Lei da Concorrência, prejudicando outras empresas e consumidores ${ }^{1}$. $\mathrm{Na}$ investigação de casos de concentrações empresariais - como fusões, aquisições, joint ventures, entre outras -, a autoridade antitruste brasileira é responsável por autorizá-las ou proibi-las, verificando se essas uniões prejudicam ou não a concorrência em

1. No Brasil, uma nova lei de concorrência, Lei n. 12.529, de 30 de novembro de 2011, entrou em vigor em 30 de maio de 2012, substituindo a lei anterior (Lei n. 8.884 de 1994) e transferindo todo o procedimento de instrução processual para o Cade, anteriormente compartilhado com a extinta Secretaria de Direito Econômico do Ministério da Justiça e com a Secretaria de Acompanhamento Econômico do Ministério da Fazenda. 
algum mercado. Entre as práticas empresariais consideradas “anticompetitivas”, que são investigadas quando há uma denúncia ou algum indício de que foram realizadas, estão a prática de cartel, preço predatório e venda casada ${ }^{2}$. Se o tribunal do Cade, formado por sete membros economistas e juristas, decidir que houve conduta desse tipo, pune-se administrativamente as empresas envolvidas.

Cada caso do conselho, seja ele referente a uma concentração ou conduta, constitui um processo administrativo, que é instruído e, em seguida, julgado pelo órgão 3 . Os "atos de concentração", como são conhecidos os processos de concentrações empresariais, são instaurados quando empresas protocolam um requerimento ao Cade solicitando autorização para prosseguirem com a união desejada. Os funcionários do órgão instruem o processo por meio de uma análise que tenta obter informações sobre os mercados em que essas empresas atuam, incluindo informações sobre as outras empresas e os consumidores dos produtos ou serviços correspondentes. Essas informações indicam aos analistas a probabilidade de a fusão investigada alterar as condições de concorrência nos mercados de maneira a prejudicar outros participantes.

Para decidir se aprovam ou não uma fusão, os profissionais do Cade precisam primeiramente saber quem são os participantes do mercado analisado - todas as empresas que nele concorrem, incluindo as próprias requerentes - e quanto cada um tem de participação no mercado, ou seja, quanto cada um responde em termos de receita ou oferta de algum produto ou serviço (conhecido como o market share de cada participante). Essa informação é necessária, pois entende-se que um número pequeno de empresas participantes/concorrentes em um mercado aumenta a probabilidade da fusão requerida "concentrar" demais o mercado, produzindo uma empresa com "poder de mercado" elevado, isto é, com grande participação em relação aos outros. Por outro lado, quando um mercado possui várias outras concorrentes além das requerentes, é mais provável que a fusão não seja danosa à concorrência, pois a nova empresa não seria capaz de prejudicar outros participantes do mesmo mercado ou seus consumidores.

Baseado em uma pesquisa de campo na sede do Cade em Brasília, este artigo descreve a dificuldade enfrentada e as soluções apresentadas por funcionários do Cade quando os concorrentes de um mercado não são facilmente visualizados ou

2. Há uma grande variedade de condutas anticompetitivas. Essas condutas podem ser práticas "unilaterais", quando se trata da ação de uma só empresa, ou "coordenadas", quando duas ou mais empresas atuam em conjunto.

3. A instrução processual é realizada por servidores públicos concursados e estagiários, estudantes de direito ou economia, que trabalham no Tribunal Administrativo ou na Superintendência-Geral do Cade, localizados no mesmo edifício na Asa Norte de Brasília. Este artigo trata exclusivamente da instrução e investigação ou análise de um "ato de concentração", conforme foi realizada pelos funcionários do gabinete de um dos conselheiros do Tribunal. 
identificados na análise necessária à instrução de atos de concentração ${ }^{4}$. Com o desenvolvimento do mercado de capitais no país, cada vez mais empresas de diversos setores abrem seu capital na bolsa de valores, vendendo suas ações entre vários compradores que se tornam proprietários e, por vezes, administradores dessas empresas. Quando entidades desse tipo, cujo controle administrativo ou a propriedade acionária estão distribuídos ou dispersos entre um conjunto de pessoas físicas e jurídicas - bancos, fundos de investimento e outros acionistas -, solicitam aprovação para uma fusão, como os profissionais do Cade responsáveis pela análise antitruste definem onde uma entidade começa e acaba? Como eles identificam quem e quantas entidades efetivamente concorrem em um mercado específico, em um contexto em que empresas estão cada vez mais vinculadas financeira, jurídica e administrativamente?

Utilizando como material etnográfico os procedimentos de investigação de uma fusão no setor de educação superior privada realizados pelos profissionais do Cade, este trabalho descreve como se dá a identificação dessas entidades, ou seja, dos agentes que concorrem no mercado. Como fica claro a partir do caso apresentado neste artigo, o agente pode ser caracterizado como um "novelo" de relações de propriedade e controle empresarial, conforme denomina um conselheiro do Cade. Esse novelo ou "grupo econômico" inclui diferentes empresas, pessoas jurídicas, além de pessoas físicas que as conectam e as compõem. A descrição das práticas de identificação de concorrentes demonstra como órgãos que implementam políticas concorrenciais necessitam construir as entidades - neste caso, certo tipo de agenciamento econômico - sobre as quais o próprio governo poderá ser exercido. Essas entidades não são dadas de antemão e precisam ser definidas caso a caso. Este artigo se insere em um conjunto de trabalhos que argumentam que os regimes regulatórios ou de governo, de um lado, e os objetos ou sujeitos "econômicos", de outro, são mutuamente constituídos por meio de práticas de conhecimento que envolvem distintos conceitos, teorias, artefatos e tipos profissionais (Elyachar, 2005; Holmes, 2014; Mitchell, 2002; Onto, 2016, entre outros).

$\mathrm{Na}$ próxima seção, explico como a visualização de um possível "problema concorrencial" por parte dos analistas do Cade exige a identificação precisa dos agentes que concorrem em um mercado, sendo que esses agentes não necessariamente coincidem com as "empresas", as "firmas" ou as "pessoas jurídicas" que nele atuam.

4. A pesquisa que embasa este artigo consistiu em uma etnografia feita entre março de 2012 e agosto de 2013 sobre a análise e o julgamento dos processos administrativos do Cade. O trabalho de campo foi realizado no gabinete de um dos conselheiros do Tribunal do Cade e em uma das coordenadorias de análise antitruste da Superintendência-Geral do órgão. A pesquisa resultou em uma tese de doutorado, defendida no Programa de Pós-graduação em Antropologia Social do Museu Nacional da Universidade Federal do Rio de Janeiro. 
Na terceira seção, demonstro como o desenvolvimento do mercado financeiro tem dificultado essa identificação. Em seguida, apresento uma descrição dos procedimentos que foram realizados para identificar um concorrente na análise de uma fusão empresarial no ano de 2013. Concluo com algumas observaçóes a respeito do modo como a sociologia e a antropologia têm se debruçado sobre o tema dos agentes ou agenciamentos econômicos.

\section{Das pessoas jurídicas aos agentes econômicos}

O “xerife da concorrência”, como a imprensa denomina por vezes o Cade, é conhecido no Brasil pelo julgamento de fusões entre grandes empresas, como aquelas entre a Brahma e a Antarctica, a Gol e a Webjet ou a Sadia e a Perdigão. Mais recentemente, o órgão tem chamado a atenção pelas investigações de condutas empresariais ilícitas, principalmente cartéis de processos licitatórios, como o "cartel do metrô" de São Paulo ou aqueles mencionados na Operação Lava-Jato da Polícia Federal. A legislação concorrencial, entretanto, não restringe seu escopo apenas a certas empresas de tamanho suficientemente grande para serem largamente conhecidas do público. A lei sequer define um tipo específico de personalidade jurídica sobre a qual ela deve ser exercida. Conforme o artigo 31:

Esta Lei aplica-se às pessoas físicas ou jurídicas de direito público ou privado, bem como a quaisquer associações de entidades ou pessoas, constituídas de fato ou de direito, ainda que temporariamente, com ou sem personalidade jurídica, mesmo que exerçam atividade sob regime de monopólio legal (Brasil, 2011).

O “sujeito da Lei Antitruste”, como o denomina a jurista Paula Forgioni, é “qualquer um que possa praticar ato restritivo da concorrência" (2013, p. 145, grifo meu). No entanto, esses tipos de ato são ou costumam ser cometidos apenas por entidades cuja forma legal tende a ser uma pessoa jurídica, devido às tipificações legais de tais atos. Em relação aos atos de concentração, diz a lei, no artigo 88, que:

[...] serão submetidos ao Cade pelas partes envolvidas na operação os atos de concentração econômica em que, cumulativamente: I - pelo menos um dos grupos envolvidos na operação tenha registrado, no último balanço, faturamento bruto anual ou volume de negócios total no País, no ano anterior à operação, equivalente ou superior a $\mathrm{R} \$$ 400.000.000,00 (quatrocentos milhões de reais); e II - pelo menos um outro grupo envolvido na operação tenha registrado, no último balanço, faturamento bruto anual ou volume de negócios total no País, no ano anterior à operação, equivalente ou superior a $\mathrm{R} \$ 30.000 .000,00$ (trinta milhões de reais) (Brasil, 2011). 
Essa qualificação dos atos que devem ser notificados ao Cade implica, na prática, que apenas empresas relativamente grandes enviam pedidos de aprovação de atos de concentração. Por outro lado, no sistema econômico que caracteriza países industrializados, não são indivíduos, mas sim sociedades empresariais aquelas responsáveis pelas produção, distribuição e comercialização da maior parte dos produtos e dos serviços consumidos pela população. As infrações à ordem econômica, apontadas na introdução, são cometidas, portanto, por essas sociedades, que concorrem com outras nos mais diferentes mercados. A forma legal capaz de estruturar empresas que exercem tais condutas ou que possuem tamanha escala de faturamento é, na prática, aquela de uma pessoa jurídica.

Essa indefinição ou não especificação da personalidade jurídica do sujeito administrado pela legislação concorrencial não deve ser entendida como uma falha do legislador, mas sobretudo como uma característica da própria política antitruste, que baseia suas decisões em análises econômicas sobre o funcionamento dos mercados e das empresas. Nessas análises, as formas jurídicas nas quais as partes envolvidas em uma fusão se estruturam - seja na forma de sociedades anônimas, abertas ou fechadas, seja na forma de sociedades limitadas, pessoas físicas, entre outras - são menos relevantes que o modo como essas partes agem e se relacionam com outros participantes do mercado, ou seja, é a definição de quem concorre em um mercado, quem é o "agente econômico" específico, qualquer que seja sua personalidade jurídica, que importa na análise do órgão antitruste 5 .

Ao receber um requerimento de concentração empresarial enviado por duas pessoas jurídicas, o papel do Cade, como já dito, é verificar se essa união será prejudicial para outros concorrentes ou para os consumidores dos mercados afetados pela fusão. Esse prejuízo à concorrência tem como base o capítulo II, artigo 36, da legislação concorrencial, que especifica:

Constituem infração da ordem econômica, independentemente de culpa, os atos sob qualquer forma manifestados, que tenham por objeto ou que possam produzir os seguintes efeitos, ainda que não sejam alcançados: I - limitar, falsear ou de qualquer forma prejudicar a livre concorrência ou a livre-iniciativa; II - dominar mercado relevante de bens ou

5. Vale notar que se o direito se utiliza da noção de pessoa, seja ela física ou jurídica, concedendo a quem pode ser assim definido direitos e responsabilidades equivalentes, a teoria econômica faz uso da noção de "agente" para denominar qualquer entidade que atua em um determinado mercado, produzindo ou consumindo produtos e serviços, seja um "indivíduo" ou uma "firma" (categorias usuais da chamada microeconomia). O uso da noção de agente implica que a atenção da teoria econômica está precisamente voltada ao comportamento econômico das entidades, em especial ao modo pelo qual elas tomam decisões e fazem escolhas relativas ao consumo ou à produção. 
serviços; III - aumentar arbitrariamente os lucros; e IV - exercer de forma abusiva posição dominante. (Brasil, 2011)

E logo em seguida:

$\$ 2^{\circ}$ Presume-se posição dominante sempre que uma empresa ou grupo de empresas for capaz de alterar unilateral ou coordenadamente as condições de mercado ou quando controlar $20 \%$ (vinte por cento) ou mais do mercado relevante, podendo este percentual ser alterado pelo Cade para setores específicos da economia (Idem, ibidem).

A legislação fornece, portanto, alguns requisitos ou indicativos para balizar a análise e a investigação antitruste referente a atos de concentração. Segundo o texto da lei, os atos que buscam "dominar um mercado" constituem "infrações à ordem econômica". Contudo, a caracterização do "domínio" do mercado e da possibilidade de seu "abuso" por parte das requerentes faz uso de um critério de "participação" nos mercados afetados, os market shares. Esse critério numérico fornece aos analistas um indício da possibilidade de existência de uma infração, isto é, tecnicamente falando, da possibilidade de "exercício de poder de mercado". No caso brasileiro, se a futura nova empresa, que resultará da união de duas ou mais requerentes, tiver uma participação superior a 20\% em algum dos mercados afetados, os analistas do Cade podem suspeitar que a fusão será prejudicial à concorrência do mercado, ou seja, prejudicial para outros concorrentes ou consumidores.

$\mathrm{Na}$ prática, isso significa que, quando um requerimento de fusão é recebido pelos funcionários responsáveis pela instrução processual do Cade, se deve verificar qual a participação das empresas requerentes nos "mercados relevantes", ou seja, nos mercados mais afetados pela fusão. A participação de cada concorrente é estimada pela quantidade de produtos que cada um vende no mercado ou pelo faturamento de cada um deles. Essas informações são trazidas pela própria requerente em sua petição inicial e são confirmadas por ofícios endereçados a todos os possíveis concorrentes que o órgão antitruste conseguiu identificar nos mercados afetados.

Porém, para se estimar a participação de cada concorrente em um mercado, é necessário, antes disso, definir previamente e precisamente quem são os agentes que concorrem nos mercados apontados. Cada um deve ser concebido como uma unidade econômica separada, que age de forma independente e concorre com os outros pela venda de cada uma das categorias de produtos mencionados; um agente ontologicamente equiparado, conforme a assunção da teoria econômica, a um indivíduo racional e interessado. Caso contrário, suas participações nos mercados não poderiam ser mensuradas nem muito menos somadas. Essa identificação dos 
agentes econômicos não costuma ser difícil, pois, na grande maioria dos processos instruídos pelo Cade, os responsáveis pela análise normalmente consideram que as pessoas jurídicas que enviaram o requerimento de concentração são também as entidades que concorrem entre si nos mercados analisados. As pessoas jurídicas quase sempre são tomadas como representando, na prática, diferentes agentes econômicos.

Contudo, a identificação de entidades econômicas concorrencialmente autônomas pode também ser bastante complexa. Com o desenvolvimento cada vez maior do mercado financeiro no Brasil, a equiparação entre certas pessoas jurídicas com certos agentes de um mercado tornou-se um problema, pois os próprios limites desses agentes ou, melhor dizendo, dos concorrentes de um mercado ultrapassam aqueles definidos pelas formas jurídicas adotadas pelas empresas requerentes ou pelas marcas empresariais conhecidas. Quando uma empresa A e B, atuantes em um mesmo mercado, são propriedade de um fundo de investimento C, como é possível saber se A e B são concorrentes no mercado, considerando que suas ações podem estar sendo coordenadas por meio de um mesmo corpo administrativo?

\section{Questões de fundo}

A dificuldade do órgão antitruste em definir quem e quantos são os concorrentes em um mercado específico é um problema relativamente recente no Brasil. Como vimos, na maior parte dos casos, as pessoas jurídicas que enviam requerimentos para unir-se com outras podem ser consideradas, para efeito de análise, como sendo os agentes que concorrem nos mercados. Essa consideração só é possível quando os proprietários e os controladores das empresas requerentes não possuem parcelas de outras ou, dito de outro modo, quando a propriedade das sociedades empresariais está nas mãos das mesmas pessoas físicas que as controlam administrativamente. Ainda hoje a maioria das empresas brasileiras tem como proprietários e administradores uma família, tornando simples a reunião de empresas, seus proprietários e administradores em uma única unidade econômica independente - um só concorrente.

Porém, o desenvolvimento do mercado de capitais e, principalmente, o crescimento dos fundos de investimento têm tornado mais complexa a visualização dos proprietários e controladores das empresas. O crescimento do mercado financeiro tem promovido a dispersão da propriedade, ao possibilitar a posse de títulos e ações empresariais por qualquer interessado que esteja disposto a adquiri-los. Se a propriedade de uma empresa e, consequentemente, sua administração podem ser distribuídas entre um grande número de pessoas físicas e/ou jurídicas, torna-se mais difícil saber onde estão as fronteiras entre uma empresa e outra, quais são seus limites. Cada vez mais as empresas estão relacionadas por meio de proprietários ou 
administradores em comum, o que confunde o trabalho de um órgão que precisa definir claramente, como exposto na seção anterior, os agentes que concorrem nos mercados, visando a obter uma estimativa de sua participação. Como precisar quem são os agentes autônomos e independentes de um mercado quando as pessoas jurídicas e físicas que têm a propriedade acionária e o controle administrativo de várias empresas estão relacionadas?

$\mathrm{Na}$ recente jurisprudência do órgão, esse problema tem sido mais frequente em casos em que as requerentes de um ato de concentração são propriedade de fundos de investimento, que também as controlam, gerando uma "sensível questão concorrencial”, segundo os funcionários do Cade. Caso um fundo possua ações e o controle administrativo de mais de uma empresa em um único mercado, ele poderia influenciá-las ao mesmo tempo, fazendo com que não concorressem entre si, pois isso seria prejudicial aos interesses do fundo. A questão enfrentada pelos analistas é como saber se a pessoa jurídica que enviou o requerimento de fusão concorre com as outras empresas do mesmo mercado quando um fundo de investimento possui ações tanto dela quanto de algumas das outras, supostamente suas concorrentes. Será que os investimentos de um fundo, quando divididos entre várias empresas de um único mercado, pode acabar tornando todas essas empresas parte de um mesmo grupo que agiria em comum acordo e orientação? Se este for o caso, todas essas empresas que receberam investimentos não poderiam ser consideradas concorrentes entre si nem agentes econômicos distintos, mas sim parte de um único agente ou grupo econômico.

Embora relativamente recentes no Brasil, problemas e questões de política pública decorrentes do desenvolvimento do mercado de capitais já eram comuns há muito tempo em países como os Estados Unidos. O próprio surgimento da política antitruste naquele país estava ligado ao combate a grandes empresas, muitas delas formando conglomerados atuantes em vários setores da economia. No final do século XIX, as corporations, empresas organizadas juridicamente para permitir e incentivar mais facilmente a dispersão acionária, expandiam-se enormemente no país ${ }^{6}$. Nessa época, a chamada separação, ou "dissociação", da propriedade acionária e do controle administrativo passou a ser considerada uma questão econômica, jurídica e social relevante (Barrionuevo Filho, 1987).

Entre os pensadores sociais que tinham interesse particular no fenômeno da separação entre propriedade e controle, produzida pela forma corporativa das empresas, pode-se mencionar Karl Marx e Marcel Mauss Para os dois autores, as corporações,

6. Não há um equivalente exato no direito brasileiro para a figura jurídica da "corporação" (corporation) norte-americana. A figura mais próxima seria uma "sociedade anônima por ações". 
por serem caracterizadas por formas coletivas de propriedade, prenunciavam uma socialização do capital por vir . As “empresas públicas” (public companies), como são chamadas as empresas abertas no mercado de ações norte-americano, eram consideradas por Marx “a abolição do modo de produção capitalista dentro do próprio modo de produção capitalista, e assim, uma contradição que se autoanula, que à primeira vista se apresenta como um mero ponto de transição para uma nova forma de produção" (citado em Barkan, 2012, p. 193). Marcel Mauss, em manuscritos recentemente reeditados, concorda com a análise de Marx, identificando na tendência à diluição da propriedade, ou seja, no surgimento das sociedades comerciais anônimas, um prelúdio à socialização ou, em suas palavras, à nacionalização do capital (Mauss, 2013). No capítulo denominado "Os fatos econômicos", quase integralmente dedicado a uma análise da formação e dos efeitos dos cartéis e dos trustes norte-americanos, Mauss defende as novas "coletividades capitalistas" por seu "caráter público", pois "não somente a propriedade mas também sua gestão são levadas ao conhecimento do mercado, da assembleia de cidadãos da nação, podendo ser julgadas pelo valor presente e futuro - sobretudo futuro - e podendo ser contadas" (Idem, p. 304).

Outros pensadores eram muito mais céticos quanto aos benefícios dessas novas estruturas empresariais. Em 1923, o economista institucionalista Thorstein Veblen, na sua última obra, Absentee ownership: business enterprise in recent times, apontava o fato de que as modernas corporações norte-americanas não tinham mais um proprietário bem definido, pois a propriedade estava dividida entre centenas de acionistas na bolsa de valores, e profeticamente previa que isso poderia causar crises econômicas pela excessiva orientação financeira e pouco produtiva dessas novas organizações. Alguns anos depois, os juristas Adolf Berle e Gardiner Means, no clássico The modern corporation and private property (1932), demonstraram empiricamente que a separação entre propriedade e controle havia se tornado uma característica definidora das empresas do período. O controle administrativo estava agora a cargo de um indivíduo ou um grupo de indivíduos selecionados para o conselho de diretores da empresa (Berle e Means, 1932, p. 66), que poderiam ser ou não proprietários. Para eles, o crescimento de tais corporações poderia gerar concentrações econômicas excessivas nos mercados. Essas possíveis consequências danosas para a concorrência deram origem a estatutos legais, como o Celler-Kefauver Act, em 1950, que proibia que uma empresa comprasse ações de outra caso a concorrência entre as duas fosse futuramente reduzida (Sklar, 1988).

7. Marx se referia às corporações inglesas da metade do século XIX, em geral instituídas pelo poder público, enquanto Mauss se referia às corporações norte-americanas privadas, em especial os trustes da virada do século XIX para o XX. 
A separação entre os proprietários e os controladores das empresas também gerou grande interesse na sociologia organizacional a partir dos anos de 1980. Esses trabalhos, que acabaram sendo considerados fundantes da chamada "nova sociologia econômica”, procuraram explicar, por meio de variáveis institucionais, relacionais ou políticas, o modo como as organizações se comportam. Tendo em vista que a propriedade dessas organizações estava distribuída entre muitos acionistas, entre eles famílias, companhias de seguro, bancos, fundos de pensão e de investimento, e que sua administração poderia ser direcionada tanto por esses proprietários como por gerentes, conselheiros e diretores das empresas, pesquisadores tentavam determinar quais eram os fatores - relações pessoais (Burt, 1983; Mintz e Schwartz, 1985), posição no "campo organizacional” (DiMaggio, 1985; Fligstein e Brantley, 1992), "concepções de controle" (Fligstein, 1990), entre outros - que influenciavam a formulação das decisões e dos objetivos empresariais. Em resumo, parte da literatura sociológica procurava esclarecer como as empresas ou outras organizaçóes se comportavam num ambiente em que as corporações estão inseridas - embedded (Granovetter, 1985) -, em um conjunto de relações mais ou menos formais com outras organizações, até mesmo com o Estado.

Este artigo não oferece uma explicação adicional às abordagens sociológicas - ou econômicas (Fligstein e Brantley, 1992) - sobre como decisões organizacionais são tomadas ou ainda sobre os potenciais danos ou benefícios de novas formas organizacionais. Como fica claro na próxima seção, muitos dos argumentos utilizados pelos sociólogos, inclusive suas técnicas de investigação, são utilizados pelos próprios analistas do Cade para explicar como as ações empresariais podem estar interligadas e, por vezes, direcionadas ao mesmo objetivo. O conhecimento sobre quem controla administrativamente as empresas, tendo em vista compreender suas orientações, é um desafio da própria análise antitruste, não apenas de sociólogos ou economistas. Porém, essa questão é apenas parte do problema mais essencial para a decisão antitruste, a saber, a identificação de quem são os agentes que concorrem no mercado analisado para definir suas respectivas participações e, assim, estimar o impacto da fusão ou aquisição empresarial. Como podemos ver na próxima seção por meio de alguns procedimentos de análise de uma aquisição no mercado de ensino superior privado, a política antitruste explicita a necessidade de uma concepção pragmática das agências econômicas em concorrência num mercado, levando em conta as relações de propriedade ou administrativas entre pessoas físicas e jurídicas. 
Durante seis meses acompanhei o trabalho de investigação necessário à instrução de processos, realizado pelo gabinete de um dos conselheiros do Tribunal Administrativo de Defesa Econômica do Cade. O Tribunal, composto por seis conselheiros mais o presidente do órgão, tem como missão instruir e julgar os processos administrativos. Cada um dos gabinetes do terceiro andar da sede do Cade em Brasília costuma abrigar três ou quatro assessores e um ou dois estagiários que produzem ofícios, fazem pesquisas e redigem relatórios ou parte dos votos que o conselheiro leva a julgamento. Em uma manhã de novembro de 2012, uma assessora de outro gabinete entrou na sala em que eu e outros quatro funcionários estávamos e perguntou se alguém já havia utilizado as ferramentas de um website de nome MarketVisual. Como nenhum de nós havia ouvido falar desse website, ela nos explicou sua finalidade, mostrando, em uma folha impressa, a Figura 1.

FIGURA 1

Rede de relações com base em Ângela Rodrigues*

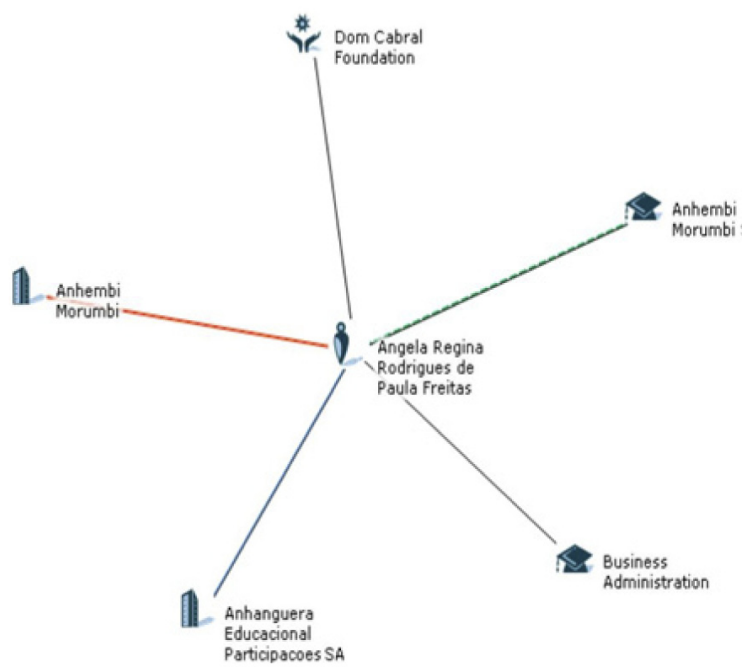

*Essa imagem está disponível nos autos do processo no site do Cade (www.cade.gov.br) em preto e branco. Para que as cores, que são e foram tão importantes na investigação empreendida pela assessora, fossem visualizadas, recorri ao site www.marketvisual.com para uma busca, gratuita e de livre acesso, pelo nome de Ângela de Castro Rodrigues. O site forneceu a mesma imagem colorida que constava do voto do conselheiro antes que uma cópia fosse digitalizada e disponibilizada no sítio do órgão antitruste em preto e branco.

Fonte: Cade (2013, p. 1896).

8. O material empírico utilizado nesta seção resultou da observação de partes da investigação realizada durante a instrução do processo de n. 08012.0038886/2011-87, além de conversas e entrevistas com os responsáveis por esse trabalho. Utilizou-se também a versão pública dos autos do processo, cujo acesso foi feito pelo sítio eletrônico do Cade (www.cade.gov.br) em 15 de fevereiro de 2014. 
Segundo a assessora, o website colecionava informações públicas de sociedades abertas no Brasil e no exterior, obrigatoriamente disponibilizadas conforme instrução da Comissão de Valores Mobiliários (cvM). O MarketVisual reúne informações relativas à estrutura societária, financeira e administrativa das empresas e as disponibiliza por meio de tabelas ou imagens na forma de organogramas ou redes ${ }^{9}$. Tais tabelas ou imagens identificam diferentes tipos de relação entre pessoas físicas e jurídicas. Na sua investigação, a assessora Camila buscou na ferramenta o nome de Ângela Rodrigues e verificou que ela tinha uma "ligação de caráter administrativo" com a empresa Anhanguera, representada pela linha azul, e uma "ligação de caráter financeiro", representada pela linha vermelha, com a Anhembi Morumbi, além de outras relações que não a interessavam tanto. Para a assessora, o mapa era mais uma prova de que ela estava realmente no "caminho certo da investigação", que buscava provar que duas supostas concorrentes faziam, na verdade, parte do mesmo "grupo econômico", ou seja, poderiam ser consideradas uma só concorrente - um só agente no mercado. Isso porque duas concorrentes estavam conectadas por uma mesma pessoa representada no centro da rede.

O processo pelo qual Camila era responsável envolvia a aquisição das sociedades Instituto Grande $\mathrm{ABC}$ de Educação e Ensino s/C Ltda. (IGABC) e Novatec Serviços Educacionais Ltda., ambas pertencentes ao Grupo Anchieta e localizadas na região do ABC paulista. O IGABC presta serviços na área de ensino superior e mantém a Faculdade Anchieta e a Novatec, que atuam na mesma área. Mantém também a Faculdade de Tecnologia Anchieta e o Colégio Anchieta. As duas sociedades estavam sendo adquiridas pela Anhanguera Educacional Ltda., que desenvolve, por sua vez, uma série de atividades de prestação de serviço de ensino superior no país, sendo, naquele ano, a "maior organização privada com fins lucrativos do setor de ensino profissional do Brasil e a maior empresa de capital aberto do setor de Educação em valor de mercado" (Cade, 2013, p. 1881). A Anhanguera tinha 54 campi, 450 polos de ensino à distância e mais de 650 centros profissionalizantes.

Alguns dias depois de a assessora responsável pela instrução desse ato de concentração me apresentar e me introduzir ao software que tanto a interessava, conversei com ela para saber como tinha chegado na investigação ao nome de Ângela e por que essa "pessoa física" teria alguma relevância para a análise que, aparentemente,

9. O website MarketVisual é uma empresa norte-americana fundada em 2003 e baseada em Seattle, Estados Unidos, que oferece, pelo valor de us \$19,95 mensais, um serviço de mapeamento e visualização de redes de relações entre pessoas físicas e jurídicas por meio da coleta de informações públicas de empresas abertas em diversos países. Como diz o próprio website da empresa que a controla, o MarketVisual é uma "ferramenta de pesquisa para profissionais legais, de risco e de compliance para descobrir conexões ocultas entre entidades empresariais e profissionais" (IntellectSpace, 2016). 
não parecia que fosse resultar no impedimento da fusão, como ela mesma me disse. Primeiramente, ela contou que havia descoberto algo que já havia sido uma fonte de preocupação entre alguns conselheiros do Cade durante julgamentos. Estes apontavam para uma crescente aquisição de participaçóes societárias por parte de fundos de investimento em empresas que atuavam no mercado de educação superior privada brasileiro. Como relatado no voto do conselheiro-relator do processo instruído, o jurista Alessandro Octaviani, a formação de grandes grupos privados de educação no país é um processo "sem precedentes na história mundial" (Idem, p. 1859). Dos cinco maiores grupos educacionais brasileiros, quatro são comandados por empresas do setor financeiro (Idem, p. 1861) ${ }^{10}$. No caso relatado, Camila descobriu pela internet, tanto em reportagens como no sítio eletrônico da própria requerente, que duas empresas do mercado de educação superior privada, a Anhanguera, empresa adquirente, e a Anhembi Morumbi, uma outra suposta concorrente, tinham alguma forma de relação por meio de pessoas jurídicas e físicas.

Segundo a reportagem "Duas concorrentes e um professor em comum", publicada no jornal O Estado de São Paulo em 11 de junho de 2012 e encontrada pela assessora, o "professor Gabriel”, como era conhecido, havia vendido o "controle" administrativo da Anhembi Morumbi, o equivalente a $51 \%$ da propriedade da empresa da qual fora fundador, para uma multinacional do setor de educação, a Laureate Education Inc. Contudo, mesmo sem o controle da universidade, que supostamente estaria nas mãos dos acionistas majoritários, ele continuava "dando palpites na administração dos sócios" (Idem, p. 1883). A empresa responsável por essa reestruturação societária da Universidade Anhembi Morumbi era uma empresa conhecida de consultoria financeira e gestão de fundos, Pátria Investimentos, cujos executivos eram conhecidos da filha de Gabriel, Ângela Rodrigues, que, por sua vez, trabalhava no departamento financeiro da universidade.

Para a assessora, a questão "começa a se complicar" quando, de acordo com a reportagem, dois anos depois da venda parcial da Anhembi Morumbi, o Pátria foi responsável também pela abertura de capital da Anhanguera. Para isso, o Pátria criou um fundo específico, o Fundo de Educação para o Brasil (FEBR), que comprou 17\% das ações da Anhanguera, sendo que a “família Rodrigues”, proprietária da Anhembi

10. Como consta no voto do conselheiro, o Grupo Estácio é controlado pelo fundo GP Investments; o Grupo Anhanguera, pelo banco e fundo Pátria; a Kroton, pelo fundo Advent Internationale; a Anhembi Morumbi Laureate Education, pelo fundo norte-americano KKR (Kohlberg Kravis Roberts). Apenas a Unip naquele momento não tinha um fundo de investimento como proprietário ou controlador. O conselheiro ainda enfatizou a dimensão desses investimentos afirmando que entre as "quinze maiores empresas educacionais do país, nove possuem um fundo ou banco de investimentos na sua estrutura de gestão e governança” (Cade, 2013, pp. 1860-1861). 
Morumbi, garantiu, por meio de uma negociação, $70 \%$ de participação nesse fundo. Mesmo com apenas $17 \%$ das ações, o FEBR, uma pessoa jurídica, tornou-se a acionista controladora da Anhanguera, segundo a reportagem. Camila descobrira, portanto, que o fundador da Universidade Anhembi Morumbi, Gabriel Rodrigues, que continuava influente nas decisões de sua empresa, era também um dos acionistas de um fundo que, por sua vez, tinha ações e controlava a Anhanguera.

Como a assessora explicou, a "questão Gabriel” gerava uma dificuldade prática para a análise do mercado de educação superior privada, no ABC e em todo o país, que exigia determinar a participação de mercado da requerente Anhanguera. Para Camila, mesmo que o caso dissesse respeito à aquisição de faculdades de uma terceira empresa - Anchieta - era necessário saber quanto a Anhanguera possuía de participação de mercado e qual era o tipo de relação entre ela e uma suposta grande concorrente, a Anhembi Morumbi. Caso a presença comum de Gabriel impusesse às duas empresas um comportamento tal que inviabilizasse a concorrência entre elas, a participação de mercado das duas empresas, Anhanguera e Anhembi Morumbi, teria que ser considerada em conjunto, pois “atuariam como um só agente no mercado”.

Além da pesquisa em jornais, revistas e sítios da internet, a assessora procurou por informações relevantes em registros das juntas comerciais do Distrito Federal, dos estados de São Paulo, Rio de Janeiro e Minas Gerais, que são acessíveis pelos seus respectivos sítios eletrônicos. Essas e outras informações colocaram em dúvida a declaração prestada pela requerente Anhanguera na petição inicial, na qual afirmava que nenhum membro da diretoria ou do conselho do grupo educacional exercia função de conselheiro ou de diretor em empresas atuantes no mesmo setor. Segundo constava da Ata da Reunião do Conselho de Administração da Anhanguera de 15 de setembro de 2010, documento enviado ao Cade pela requerente, Ângela Regina Rodrigues de Paula Freitas, filha de Gabriel Rodrigues, era membro do conselho de administração da empresa. A assessora encontrou, entretanto, um registro na Junta Comercial do Estado de São Paulo (Jucesp) que apontava Ângela também como diretora da ISCP, a sociedade mantenedora da Universidade Anhembi Morumbi/ Laureate (Idem, p. 1888). Ângela também tinha outras relações comerciais e societárias que a uniam às duas supostas concorrentes. Por exemplo, de acordo com a Ata da Assembleia Geral Extraordinária da Anhanguera, de 29 de outubro de 2010, Ângela Rodrigues tem escritório na rua Casa do Ator, n. 99, no bairro da Vila Olímpia, em São Paulo. Porém, conforme a consulta realizada na Jucesp, esse mesmo endereço coincidia com o de um dos campi da Universidade Anhembi Morumbi Laureate (Idem, p. 1889). A utilização do MarketVisual e da rede produzida por esse meio apenas produziu mais uma evidência de que Ângela, assim como Gabriel, estava de alguma forma vinculada a duas empresas supostamente concorrentes. 
A assessora encontrou ainda divergências nos próprios documentos enviados pela requerente da concentração que confirmaram a "influência da família Rodrigues" e do fundo gerido pelo Pátria, o FEBR, no qual os familiares têm participações, na definição das políticas estratégicas e na gestão da Anhanguera. A requerente afirmava na petição inicial que não havia nenhum acordo entre seus acionistas ou cotistas que incluísse regras para a administração da empresa, tendo em vista que o FEBR tem apenas 17,24\% da propriedade da Anhanguera. No regulamento da assembleia geral de cotistas, entretanto, enviada como resposta a um ofício produzido pela assessora, afirma-se que o fundo FEBR tem garantida a indicação de membros para o conselho de administração da empresa e a "titularidade das ações que compõem o bloco de controle" (Idem, p. 1890). O próprio Gabriel havia afirmado, em petição ao Cade, que na Anhanguera era "apenas acionista”, tendo junto com a família somente 7,5\% do FEBR. Mas, em contradição com essa afirmação, um documento enviado pelos próprios advogados atestava que essa participação era nada menos que dez vez maior (75,7\%), o que dava à "família Rodrigues" a direção do FEBR e, por consequência, a direção da Anhanguera.

Segundo o voto do conselheiro-relator do processo, tendo como base a investigação realizada por Camila, pode-se identificar tanto um "novelo de relações (ou participações) societárias", ou seja, um conjunto de relações de propriedade, como um "novelo de dirigentes", um conjunto de relações de controle administrativo, que se estende entre a Anhanguera e a Anhembi Morumbi, envolvendo pessoas jurídicas, fundos de investimento que investem e administram essas empresas, e pessoas físicas, integrantes da "família Rodrigues". Segundo o conselheiro-relator, a instrução do processo conseguiu revelar o "verdadeiro organizador central das decisões, o punctum saliens empresarial: o arranjo comandado pelo sr. Gabriel Rodrigues e família, com o auxílio do Pátria, que submete duas concorrentes, Anhanguera e Anhembi Morumbi Laureate, às suas estratégias, tornando incidente a definição lexical do vocábulo 'sinergia'; 'ato ou esforço de diversos órgãos na realização de uma função'” (Idem, p. 1895). Em um diagrama que consta do voto, o conselheiro-relator tornou mais visível esse "novelo", "núcleo organizador central" ou "arranjo", como ele alternadamente denominou, baseando-se nas participações societárias das duas supostas concorrentes (Figura 2).

O "núcleo organizador real", mais uma denominação para o mesmo "arranjo", reúne as duas empresas, os fundos de investimento que as controlam e as pessoas físicas, integrantes da família Rodrigues, que possuem parte da propriedade e o controle dos fundos. Para o relator, citando um voto anterior do conselheiro Carlos Ragazzo, esse núcleo pode ser qualificado como "grupo econômico", conforme a denominação adotada no direito econômico, já que se pode reconhecer a existência 
FIGURA 2

Quadro intitulado "Novelo de participações societárias"

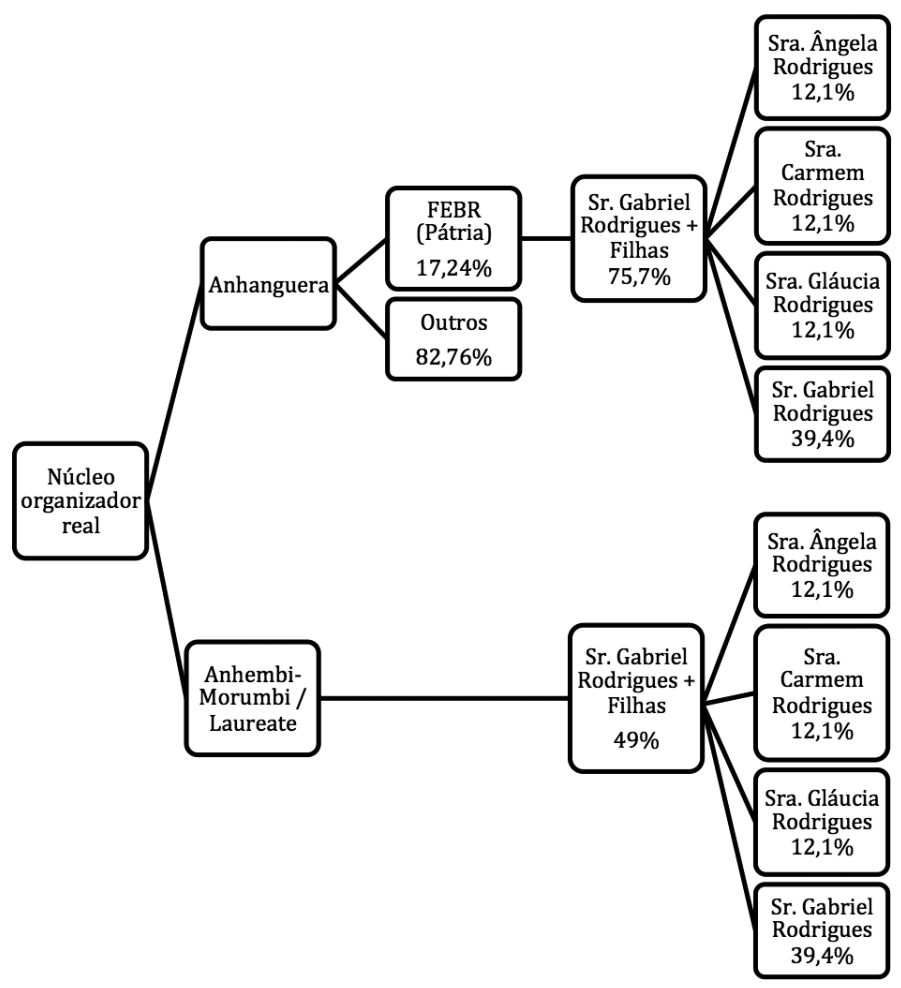

Fonte: Cade (2013, p. 1900).

de uma "orientação concorrencial central,, definida na cúpula do referido grupo, seja qual for sua forma de constituição, da qual se espera o cumprimento pelos demais integrantes" (Idem, p. 1908). Para o conselheiro-relator, as participações e as relações entre as pessoas jurídicas e físicas tornavam razoável inferir que as duas empresas tinham conhecimento mútuo de suas ações e estratégias e que não agiriam de forma alguma em desacordo com a outra ou para prejudicá-la.

Se todas as entidades presentes nesse arranjo, pessoas físicas e jurídicas, podem ser consideradas "como se fossem uma" concorrente para fins da política de defesa da concorrência, devem ser somadas, segundo o conselheiro, "as participações e os recursos conexos dos grupos Anhanguera/Anhembi Morumbi Laureate/Pátria" (p. 1913), não apenas na instrução desse processo, mas sempre que houver a necessidade de se calcular o market share dos participantes em uma análise que envolva alguma dessas empresas. A investigação realizada neste caso conseguiu provar que a requerente Anhanguera tinha uma participação maior no mercado, tendo em vista que sua alegada concorrente, a empresa Anhembi Morumbi, estava vinculada a ela de diversas formas, de modo que só poderiam constituir um mesmo "arranjo" 
organizacional agindo de maneira coordenado. Portanto, não era possível considerar a Anhanguera e a Anhembi Morumbi como concorrentes entre si no mercado de educação superior privada.

Ao descrever seus procedimentos, o conselheiro afirmou que as participações acionárias de pessoas físicas, mesmo que minoritárias, as estratégias empresariais coincidentes e os corpos dirigentes cruzados entre empresas (a conhecida interlocking directorates estudada pelos sociólogos organizacionais) possibilitam conhecer e definir aquilo que ele chamou alternadamente de "novelo", "organizador central das decisões", "núcleo organizador real”, "grupo econômico" ou "arranjo". Esse agente econômico, concebido com base nas relações de propriedade e de controle entre pessoas físicas e jurídicas, escapa ou extrapola as formas jurídicas nas quais certas entidades se constituem e se apresentam. Segundo o conselheiro, essas formas, pelo contrário, podem acabar ocultando o verdadeiro agente que a política antitruste necessita identificar. Em um trecho do voto, o conselheiro critica o uso das formas oficiais, sejam elas administrativas ou jurídicas, como critério analítico:

[...] como sugere Mark Granovetter, aqueles que acreditam que a estrutura da empresa reside no seu organograma oficial ou nas estruturas societárias formais "não passam de bebês perdidos na floresta da sociologia”, pois a organização "formal” (e, em muitos casos, também a "informal") da sociedade empresária não são suficientes para a análise antitruste (Idem, p. 1917) ${ }^{11}$.

Dessa forma, aproximando a análise antitruste de certos estudos sociais das organizações, a análise realizada nesse caso conseguiu provar que um dos agentes econômicos do mercado, o requerente, possuía uma participação maior no mercado, tendo em vista que seu suposto concorrente, Anhembi Morumbi, era constitutivo de um mesmo arranjo organizacional. Essa definição do agente não resultou em um resultado diferente para a requerente Anhanguera, que teve sua aquisição aprovada pelo Cade. Os conselheiros entenderam que a concorrência nos mercados afetados na região do Grande $\mathrm{ABC}$ paulista não seria tão reduzida com a aquisição, mesmo que considerassem Anhanguera e sua suposta concorrente, Anhembi Morumbi, como parte do mesmo grupo. No entanto, as descobertas decorrentes da investigação, que enfatizaram a importância de uma análise detalhada de concentrações que envolvem fundos de investimento, construíram uma nova jurisprudência para casos no mercado de educação superior privada no Brasil.

11. O conselheiro-relator cita em nota de rodapé o conhecido artigo do sociólogo Mark Granovetter, "Economic action and social structure: the problem of embeddedness" (Granovetter, 1985). 


\section{Considerações finais}

Este artigo demonstrou como a política antitruste necessita, para ser implementada, conceber um certo tipo de agente econômico - o concorrente - tendo em vista estimar um grau de concorrência futuro para o mercado analisado por meio das participaçôes desses agentes. Somente essa identificação permite aferir se a concentração empresarial em análise ocasionará um "dano" ou "prejuízo" à concorrência dos mercados. Como explicado, essa tarefa tem se tornado mais complexa, pois as empresas requerentes dos atos de concentração são cada vez mais propriedade de um grande número de sócios, pessoas físicas ou jurídicas, que podem ou não ter um controle administrativo sobre elas. Pode-se argumentar que essa dificuldade do órgão antitruste não é muito diferente daquela que cientistas sociais já enfrentaram ao tentar conceber determinadas formas de agências em contextos variados, em que a grande quantidade de relações torna qualquer singularidade ou unidade invisível.

Desde suas origens, a literatura antropológica vem apontando as diferentes formas de agências econômicas que não se limitam a singularidades visíveis para o observador que as analisa e, mais do que isso, se estendem para além do indivíduo, usualmente considerado a unidade e o agente por excelência no pensamento econômico ocidental. Marcel Mauss ([1925] 2003), para ficar com um exemplo clássico, ao tentar descrever o agente da troca nas relaçôes, também comerciais, do kula melanésio, utilizou o conceito de personne morale para explicar as coletividades não individuais (clãs, tribos, famílias) que participam do que ele chama de "sistemas de prestações totais". "Pessoas morais" seriam os coletivos híbridos de pessoas e coisas sobre os quais recaem obrigações de dar, receber e retribuir dádivas ${ }^{12}$. $\mathrm{O}$ agente do kula seria, portanto, um coletivo de pessoas e coisas relacionadas que poderia ser distinguido de outros coletivos.

Mesmo quando investigam a economia moderna, industrial ou capitalista, sociólogos e antropólogos também têm buscado refletir sobre as noções de agência, buscando oferecer uma crítica e um complemento para abordagens consideradas "subsocializadas", tanto da ciência econômica como da sociologia. Por isso, não foi por acaso que o conselheiro citou em seu voto um dos artigos mais conhecidos do sociólogo Mark Granovetter, publicado em 1985, considerado fundante da chamada

12. "Nas economias e nos direitos que precederam os nossos, nunca se constatam, por assim dizer, simples trocas de bens, de riquezas e de produtos num mercado estabelecido entre os indivíduos. Em primeiro lugar, não são indivíduos, são coletividades que se obrigam mutuamente, trocam e contratam; as pessoas presentes nos contratos são pessoas morais: clãs, tribos, famílias, que se enfrentam e se opõem seja em grupos frente a frente num terreno, seja por intermédio de seus chefes, seja ainda dessas duas maneiras ao mesmo tempo" (Mauss, [1925] 2003, p. 190). 
"nova sociologia econômica”, para justificar uma interpretação das agências econômicas da política da concorrência em termos relacionais. Este sociólogo empregou a noção de redes sociais para explicar que toda ação econômica é necessariamente imbricada (embedded) em relações sociais. Autores mais contemporâneos como Michel Callon (2008) e Donald MacKenzie (2009), provenientes dos estudos sociais das ciências, também têm buscado oferecer uma alternativa a supostas concepções correntes da teoria econômica, chamando atenção para as condições que possibilitam conceber e construir agentes ou agências (agencements) econômicas como entidades calculadoras ou racionais. Não seria possível entender o funcionamento do mercado financeiro, por exemplo, levando em consideração apenas a agência dos humanos. As ações de operadores de mercado (traders) seriam parte de um arranjo sociotécnico que inclui "equipamentos" como calculadoras, softwares, algoritmos, documentos, entre outros “actantes”, que, em conjunto, os tornam capazes de tomar decisões econômicas.

Esses autores, e outros também - por exemplo, Bourdieu (2000) -, não estão apenas construindo um argumento crítico em relação à teoria econômica (ou mesmo aos antropólogos e sociólogos que concordavam com essa teoria), segundo a qual as unidades básicas para a análise da vida econômica poderiam ser consideradas os indivíduos racionais maximizadores de escolhas entre custos e benefícios - os homo economicus. Os autores estão basicamente descrevendo como agências econômicas são construídas ou como variam enormemente entre contextos. Neste artigo, demonstro como a questão da visualização e da concepção de agências alternativas não é apenas monopólio dos cientistas sociais, mas também dos próprios especialistas, muitos deles educados na teoria econômica moderna, responsáveis por implementarem uma política pública presente em praticamente todos os países industrializados.

A descrição de como os profissionais do Cade conceberam um agente concorrente do mercado, unindo as empresas Anhanguera e Anhembi Morumbi, ilustra como a política antitruste não está tão distante de perspectivas socioantropológicas que pensam o agente como uma rede híbrida composta de pessoas (jurídicas e físicas) e coisas (propriedade). No caso aqui observado, a identificação dos concorrentes passa também, como vimos, pela identificação de relações de propriedade e controle empresariais, que incluem também relações de parentesco (família Rodrigues), formando um "novelo" com objetivos e intenções singulares.

Se a análise concorrencial usa uma abordagem relacionalista, não é improvável que outras formas de governar a economia também tenham necessidade de produzir continuamente formas de agência econômica contextuais e específicas. Criticar o modo como alguns economistas ou certas políticas econômicas simplificam a realidade, utilizando, na prática, variações possíveis de "indivíduos maximizadores 
autointeressados", não parece ser suficiente ou mesmo válido quando consideramos a diversidade de agências ou sujeitos econômicos potencialmente concebidos e construídos por meio de políticas públicas, teorias econômicas alternativas e outras práticas econômicas, eruditas ou ordinárias. Cabe aos cientistas sociais investigarem mais profundamente as diferentes formas de agências ou sujeitos econômicos, como o "concorrente" neste caso, que atravessam e formatam modos de pensar e agir economicamente nas sociedades modernas.

\section{Referências Bibliográficas}

BARKan, Joshua. (2013), Corporate sovereignty: law and government under capitalism. Minneapolis, University of Minnesota Press.

Barrionuevo Filho, Arthur. (1987), "A separação entre propriedade acionária e controle administrativo: revisitando os clássicos". Revista de Administração de Empresas, 4 (27): 31-37.

BerLe, Adolf A. \& MeAns, Gardiner C. (1932), The modern corporation and private property. Nova York, MacMillan.

Bourdiev, Pierre. (2000), Les structures sociales de l'économie. Paris, Seuil.

Brasil. (2011), "Lei n. 12.529, de 30 de novembro de 2011 ”. Disponível em http://www.planalto.gov.br/ccivil_03/_ato2011-2014/2011/Lei/L12529.htm, consultado em 8/11/2014.

BURT, Ronald. (1983), Corporate profits and cooptation: networks of market constraints and directorate ties in the American economy. Nova York, Academic.

CADE - Conselho Administrativo de Defesa Econômica. (2013), "Voto do conselheiro Alessandro Octaviani no Processo Administrativo n' 08012.0038886/2011-87. Requerentes: Anhanguera Educacional Ltda. e Grupo Anchieta”. Disponível em www.cade.gov.br, consultado em 15/2/2014.

CAllon, Michel. (2008), "Economic markets and the rise of interactive agencements: form prosthetic agencies to habilitated agencies". In: Pinch, Trevor \& Swedberg, Richard (orgs.). Living in a material world: economic sociology meets science and technology studies. Cambridge, The mit Press.

DiMaggio, Paul. (1985), "Structural analysis of organizational fields: a blockmodel approach”. Research in Organizational Behavior, 7: 335-370.

ELYACHAR, Julia. (2005), Markets of dispossession: NGOs, economic development, and the state in Cairo. Durham, Duke University Press.

Fligstein, Neil. (1990), The transformation of corporate control. Cambridge, Harvard University Press.

Fligstein, Neil \& Brantley, Peter. (1992), "Bank control, owner control, or organizational dynamics: who controls the large corporation?”. American Journal of Sociology, 2 (98): 280-307. 
Forgioni, Paula. (2013), Os fundamentos do antitruste. 6. ed. São Paulo, Revista dos Tribunais. Granovetter, Mark. (1985), "Economic action and social structure: the problem of embeddedness". American Journal of Sociology, 3 (91): 481-510.

Holmes, Douglas. (2014), Economy of words: communicative imperatives in central banks. Chicago, Chicago University Press.

Hovenkamp, Herbert. (2005), The antitrust enterprise: principle and execution. Cambridge, Harvard University Press.

IntellectSpace. "Portfolio of solutions". Disponível em http://www.intellectspace.com/ solutions, consultado em 25/11/2016.

MacKenzie, Donald. (2009), Material markets: how economic agents are constructed. Oxford, Oxford University Press.

Mauss, Marcel. ([1920] 2013). La nation. Paris, PUF. . ([1925] 2003) "Ensaio sobre a dádiva: forma e razão da troca nas sociedades arcaixas". In:__. Sociologia e antropologia. São Paulo, Cosac Naify, pp. 183-314.

Mintz, Beth \& SCHWARTz, Michael. (1985), The power structure of American business. Chicago, University of Chicago Press.

Mitchell, Timothy. (2002), Rule of experts: Egypt, techno-politics, modernity. Berkeley, University of California Press.

OnTo, Gustavo. (2016), “O mercado como um contexto: delimitando o problema concorrencial de uma aquisição empresarial”. Horizontes Antropológicos, 45 (22): 155-184.

OsCar, Naiana. (2012), “Duas concorrentes e um professor em comum”. O Estado de S. Paulo, 11/6. Disponível em http://economia.estadao.com.br/noticias/geral,duas-concorrentes-e-um-professor-em-comum-imp-,884773, consultado em 25/11/2016.

SKLAR, Martin J. (1988), The corporate reconstruction of American capitalism, 1890-1916: the market, the law, and politics. Cambridge, Cambridge University Press.

Veblen, Thorstein. ([1923] 1996). Absentee ownership: business enterprise in recent times. Londres, Transaction.

\section{Resumo}

O agente econômico e suas relações: identificando concorrentes na política antitruste

Baseado em uma etnografia realizada no órgão governamental de defesa da concorrência do Brasil, o Conselho Administrativo de Defesa Econômica (Cade), este artigo explica a necessidade de se identificar agentes concorrentes na análise empreendida pela autarquia e descreve como essa identificação foi realizada em uma recente aquisição empresarial no setor de educação superior privada. Essa prática de identificação, comum nos casos antitruste de "atos de concentração", como fusões ou aquisições empresariais, tem se tornado mais complexa devido à maior financeirização da economia, pois diversas empresas estão interconectadas por meio de uma rede nem sempre 
explícita de relações de propriedade e/ou controle empresariais, que inclui pessoais físicas e jurídicas. $\mathrm{O}$ artigo descreve alguns procedimentos de investigação utilizados para visualizar e conceber um concorrente de mercado nesse novo contexto. Pretende-se, com essa descrição, demonstrar o modo como certas práticas governamentais de conhecimento - neste caso, relativas à regulação legal da concorrência - produzem agentes econômicos, indicando a existência de uma diversidade, nem sempre considerada na sociologia ou antropologia, de formas de agenciamento que perpassam e formatam a vida econômica.

Palavras-chave: Agente econômico; Relações; Concorrente; Práticas de conhecimento; Política antitruste; Cade.

\section{Abstract}

The economic agent and its relations: identifying competitors in antitrust policy

Based on an ethnography undertaken at the Brazilian antitrust agency, the Administrative Council for Economic Defense (Cade), this article explains the agency's need to identify competitive agents as part of its investigation into competition issues and describes the way this identification was undertaken in a recent corporate acquisition in the private higher education sector. This identification practice, common in antitrust cases related to "acts of concentration", such as corporate mergers and acquisitions, is becoming more complex due to the increasing financialization of the economy, since several companies are interconnected through networks of corporate ownership and/or control that are not always explicit. This article describes some of the investigative procedures adopted in order to visualize and conceive a market competitor in this new context. Through this description, the author seeks to demonstrate how certain government knowledge practices - in this case those related to legal regulation of competition produce economic agents, pointing to the existence of a diversity of forms of agencies that is not always taken into consideration in sociology or anthropology, but which nevertheless permeate and mold economic life..

Keywords: Economic agent; Relations; Competitor; Knowledge practices; Antitrust policy; Cade.

Texto recebido em 11/8/2016 e aprovado em 14/10/2016. DoI: 10.11606/0103-2070.ts2017. 118967.

gustavo gomes onto é pesquisador do Núcleo de Pesquisas em Cultura e Economia (NuCEC) da Universidade Federal do Rio de Janeiro e pós-doutorando PNDP-Capes do Programa de Pós-graduação em Sociologia e Antropologia (PPGAS) na mesma universidade. E-mail: gustavo. onto@gmail.com. 